Article

\title{
Characteristics of Suspended Sediment Loadings under Asian Summer Monsoon Climate Using the Hydrological Simulation Program-FORTRAN
}

\author{
Ji-Hong Jeon ${ }^{1}$, Chan-Gi Park ${ }^{2}$, Donghyuk Choi ${ }^{1}$ and Taedong Kim ${ }^{1, *}$ \\ 1 Department of Environmental Engineering, Andong National University, Andong 760748, Korea; \\ jhjeon@anu.ac.kr (J.-H.J.); cdh@anu.ac.kr (D.C.) \\ 2 Department of Rural Construction Engineering, Kongju National University, Yesan 32439, Korea; \\ cgpark@kongju.ac.kr \\ * Correspondence: tdkim@anu.ac.kr; Tel.: +82-54-820-5895; Fax: +82-54-820-6437
}

Academic Editor: Tan Yigitcanlar

Received: 1 September 2016; Accepted: 21 December 2016; Published: 28 December 2016

\begin{abstract}
The extreme variation in the amount of annual precipitation and rainfall during single events is typical of the East Asian monsoon climate and may greatly influence the characteristics of the suspended sediment load. The turbidity in Lake Imha which is the eighth largest multipurpose dam in Korea has been the cause of major water quality problems for use as drinking water. The turbidity rose to 882 NTU, and it remained over 30 NTU continuously for 170 days during 2002, as the result of significant amounts of soil erosion from the watershed during the Asian monsoon typhoon. In this study, characteristics of suspended sediment loadings under the Asian summer monsoon climate was investigated by comparing the variation of yearly suspended sediment loads and the ratio of maximum suspended sediment loads in a single event to yearly suspended sediment load from Lake Imha watershed using the Hydrologic Simulation Program-FORTRAN (HSPF). The model calibration is performed according to the 2009-2010 events, and simulation results characterized suspended sediment loadings under the Asian summer monsoon climate for 2001-2010. Water sampling and flow rate measurements were performed every $4-6 \mathrm{~h}$, and calibration was performed using hourly simulated sediment loads. The calibration results demonstrated good agreement with the observed data. The characteristics of suspended sediment loadings under the Asian summer monsoon climate are a high variance of the yearly suspended sediment load and a significant of amount of suspended sediment load during a single event influenced by the typhoon intensity. The maximum yearly suspended sediment load was 10 times higher than the minimum yearly value. About half of the yearly suspended sediment load was loaded with a single event under the Asian summer monsoon climate and the ratio of suspended sediment loads by a single event to total yearly loads ranged from $29 \%$ to $90 \%$. Structural best management practices (BMPs) to trap suspended sediment in stormwater such as stormwater ponds or wetlands rely on much more storage volume or area and non-structural BMPs to minimize soil erosion by source control such as mulching or revegetation in disturbed areas, which are important BMPs, especially in the Asian summer monsoon region.
\end{abstract}

Keywords: HSPF; calibration; suspended sediment yield; Lake Imha; East Asia monsoon climate

\section{Introduction}

The rainfall under an Asian summer monsoon climate is strongly concentrated in summer in Korea. During the summer season, significant amounts of nonpoint source pollution are generated which flow into water bodies. Soil erosion can be a major factor in water quality problems caused by the Asian summer monsoon typhoon in Korea [1]. Excessive sediment deposited onto the bottom of a 
water body can impair aquatic life and fisheries, reduce the quality of drinking water such as taste and odor, block water supply intakes, and limit recreational water use by altering channel morphology [2]. Pollution tightly attached to sediment can also cause water quality problems. Crabill et al. [3] identified sediment with high fecal coliform counts, averaging 2200 times higher than those of the water column, which causes a deterioration in water quality during the summer season in Oak Creek, Arizona, USA. The major source of phosphorus, which causes eutrophication in lakes and reservoirs, was found to be soil erosion in the Hii River basin, Japan [4].

Estimating and simulating sediment loads from watersheds is an important procedure for evaluating various scenarios in order to reduce soil erosion. One used method to estimate sediment loads is the Revised Universal Soil Loss Equation (RUSLE) [5]. RUSLE can easily estimate soil erosion loads [6], and evaluate various measured controls $[7,8]$. Another watershed model used to simulate sediment is the Soil and Water Assessment Tool (SWAT) [9]. SWAT uses a Modified Universal Soil Equation (MUSLE) for sediment simulation, and has been used to simulate sediment yield from small [10] to large scale watersheds [11]. Sommerlot et al. [12] developed a field-scale SWAT linked with RUSLE2 for estimating sediment yield, and compared the results with those of SWAT and High Impact Targeting (HIT). Hydrologic Simulation Program-FORTRAN (HSPF) is used widely to simulate the watershed hydrology and water quality, and is one of the detailed models that can be applied in both rural and urban areas [13]. The detachment and wash-off equation in HSPF was used to simulate soil erosion. A few researchers have also simulated sediment using HSPF. Ouyang et al. [14] evaluated the impact of reforestation on sediment load and water outflow, and Walton and Hunter [15] used it to analyze the land-use effects on fluxes of suspended sediments from a catchment.

One of the characteristics of sediment loads in the Asia monsoon region is that the majority of sediment transport occurs during high-flow events; thus a model's capacity for accurately capturing these rainfall events is important [11,16]. Thompson et al. (2014) [17] concluded that the use of different sampling resolution impacted the estimation of the suspended sediment loads, and sampling every seventh hour was the best frequency. The strength of HSPF for suspended sediment simulation is that it can simulate hourly pollutant loads [18]. If monitoring is performed well during a rainy day, HSPF can simulate the pattern of hourly sediment loading and estimate sediment yield. In this study, the suspended sediment loads under the East Asian monsoon climate was characterized using calibrated HSPF during 2001-2010, and HSPF was calibrated during the years 2009-2010 for simulating stream flow and suspended sediment loading at six monitoring stations within the Lake Imha watershed.

\section{Materials and Methods}

\subsection{Overview of Hydrologic Simulation Program-FORTRAN (HSPF)}

HSPF was developed based on the Stanford Watershed Model IV, which was developed to simulate the portion (the land phase) of the hydrologic cycle for an entire watershed [18]. HSPF is now available from the U.S. Environmental Protection Agency (U.S. EPA). The HSPF model can simulate the hydrologic and water quality processes on pervious and impervious land, and the hydraulic and water quality in a water body [18]. The simulation modules in HSPF used for pervious and impervious land and reach are PERLND, IMPLND, and RCHES, respectively. The fluxes and storages of sediment used to simulate PERLND are shown in Figure 1.

Kinetic energy from rainfall on the soil detaches soil particles, which are then available to be transported by overland flow. The equation that simulates detachment is shown in Equation (1), as follows [18]:

$$
\mathrm{DET}=\mathrm{DELT} 60 \times(1.0-\mathrm{CR}) \times \mathrm{SMPF} \times \mathrm{KRER} \times\left(\frac{\mathrm{RAIN}}{\mathrm{DELT60}}\right)^{\mathrm{JRER}}
$$


where DET is the sediment detached from the soil matrix by rainfall (tons/ac/interval), DELT60 is the number of hours/interval, CR is the fraction of the land covered by snow and other cover, SMPF is the supporting management practice factor, KRER is the detachment coefficient dependent on soil properties, RAIN is rainfall ( $\mathrm{mm}$ /interval), and JRER is the detachment exponent dependent on soil properties.

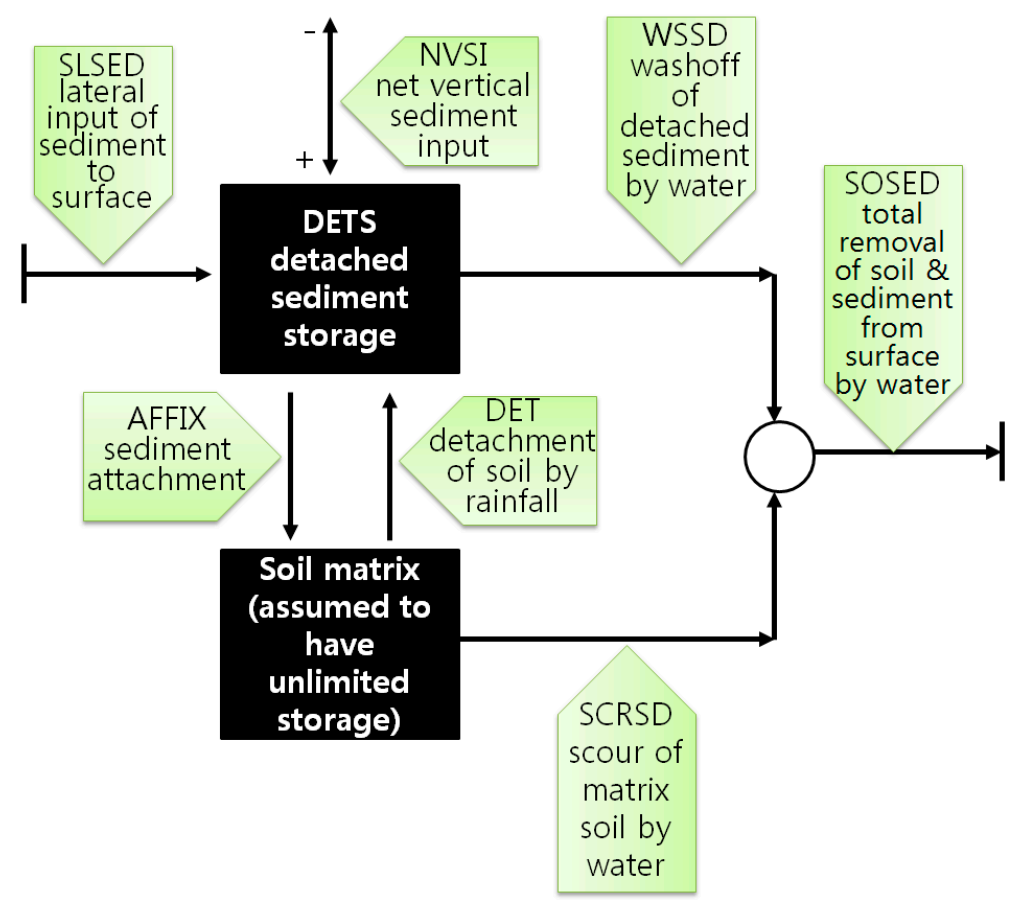

Figure 1. Flow diagram for SEDMNT section of PERLAND application module.

The wash off of the detached sediment when the storage is sufficient to fulfill the transport capacity is shown in Equations (2) and (3), as follows [18]:

$$
\begin{gathered}
\text { WSSD }=\text { STCAP } \times \frac{\text { SURO }}{(\text { SURS }+ \text { SURO })} \\
\text { STCAP }=\text { DELT60 } \times \text { KSER } \times\left(\frac{\text { SURS }+ \text { SURO }}{\text { DELT60 }}\right)^{\text {JSER }}
\end{gathered}
$$

where WSSD is the wash off of detached sediment (tons/ac/interval), STCAP is the capacity for removing the detached sediment (tons/ac/interval), SURO is the surface outflow of water (mm/interval), and SURS is the surface water storage (mm).

\subsection{Study Area}

Lake Imha is the eighth largest multipurpose dam in Korea, including a hydropower plant, and is upstream of the Nackdong River, which is the second largest river in Korea (Figure 2). The surface area and storage volume are $42.4 \mathrm{~km}^{2}$ and $6.0 \mathrm{~m}^{3}$, respectively, while the drainage area and length of the river are $1361 \mathrm{~km}^{2}$ and $98.1 \mathrm{~km}$, respectively. Lake Imha has two major tributary basins: Yongjun Creek and Banbyun Creek. Lake Imha is a major source of drinking water in the upper area of the Nadong River, but has suffered from high turbidity in the water from the impact of two typhoons: Rusa in 2002, and Maemi in 2003. The nepthelometric turbidity unit of Lake Imha reached 1221 NTU, and the high turbidity concentration in the outflow was continuous for 340 days. The long-term turbid water in Lake Imha impacted several components of the ecosystem, including the gill structures of fish [19], benthic macroinvertebrates, and the food selection of fish [20]. 

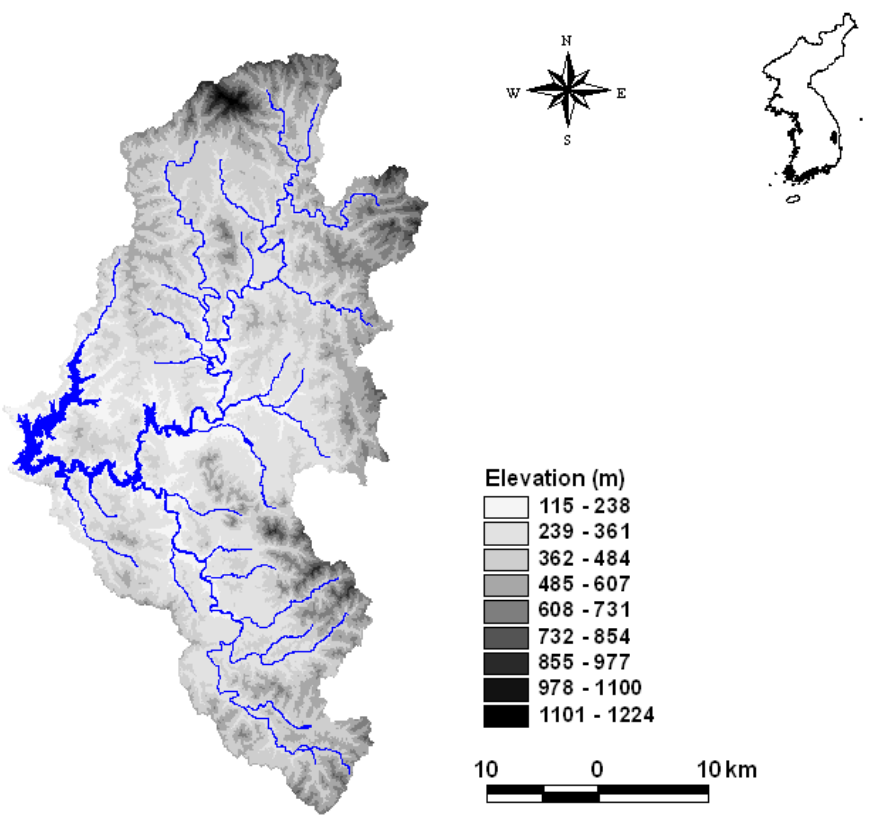

Figure 2. Study area.

\subsection{Data Preparation}

The user control input (UCI) file of HSPF was generated by the Better Assessment Science Integrating point and Non-point Sources (BASINS), which is a multipurpose environmental analysis system. BASINS requires some geographic information system (GIS) data, including Digital Elevation Model (DEM), land-use, watershed, and river data. The DEM, with a mesh size of $30 \mathrm{~m}$ (Figure 2), and the land-use coverage (Figure 3) were obtained from the Korean Ministry of Environment, and the other GIS data, such as watershed and river data, and the location of weather stations were obtained from the Korean Ministry of Land, Infrastructure and Transport. The 47 subwatersheds were delineated using the subwatershed delineation tool of BASINS with DEM (Figure 3). Hourly weather data including temperature, cloud cover, wind speed, solar radiation, and dew point temperature were obtained from the Korea Meteorological Administration, and hourly rainfall data at eight rain gage stations within the Lake Imha watershed were obtained from the Korean Water Resources Corporation (K-Water). Suspended sediment concentration and water flow rate were monitored at every 4-15 h for rainy days during 2009-2010. Some monitoring chances for peak flow were missed due to the hazardous weather conditions including wind, lightning, flooding. Land use classification covered the monitored stations, and a summary of the rainfall events used for calibration is shown in Tables 1 and 2 , respectively. Amount of rainfall ranged from 28.0 to $68.9 \mathrm{~mm}$ and, duration and maximum rainfall intensity were $4-44 \mathrm{~h}$ and $6.0-24.0 \mathrm{~mm} / \mathrm{h}$, respectively.

Table 1. Monitoring stations and watershed descriptions.

\begin{tabular}{ccccccccc}
\hline \multirow{2}{*}{ Station ID } & \multirow{2}{*}{ Area $\left(\mathbf{k m}^{2} \mathbf{)}\right.$} & \multicolumn{7}{c}{ Land Use (\%) } \\
\cline { 3 - 9 } & & Urban & Wetland & Agriculture & Forest & Water & Barren & Pasture \\
\hline ST1 & 70.9 & 0.4 & 1.1 & 4.3 & 92.8 & 0.8 & 0.5 & 0.1 \\
ST2 & 11.4 & 8.5 & 5.4 & 26.2 & 58.2 & 0.8 & 0.5 & 0.4 \\
ST3 & 21.3 & 1.0 & 2.7 & 11.3 & 83.2 & 1.3 & 0.4 & 0.1 \\
ST4 & 144.3 & 1.0 & 3.4 & 10.6 & 83.2 & 1.3 & 0.4 & 0.1 \\
ST5 & 397.4 & 1.3 & 2.8 & 10.5 & 83.2 & 1.4 & 0.6 & 0.2 \\
ST6 & 537.9 & 1.6 & 2.8 & 11.3 & 81.4 & 1.5 & 0.9 & 0.5 \\
\hline
\end{tabular}



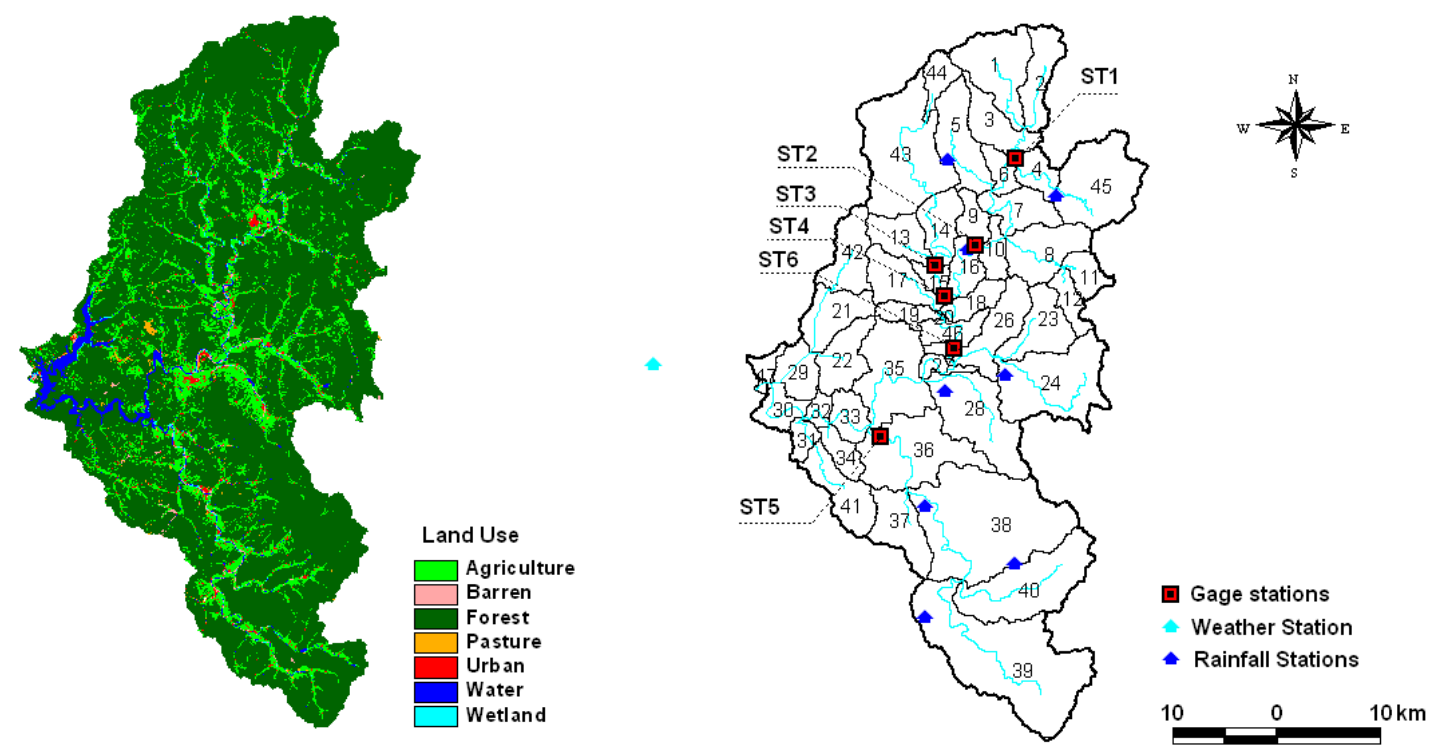

Figure 3. Land use classification and gage stations.

Table 2. Summary of rainfall events and calibrated watershed.

\begin{tabular}{ccccc}
\hline Date & Rainfall (mm) & Duration (h) & $\begin{array}{c}\text { Maximum Rainfall } \\
\text { Intensity } \mathbf{( m m} / \mathbf{h})\end{array}$ & Calibrated Watershed \\
\hline 21 May 2009 & 50.9 & 11 & 9.0 & ST1, ST2, ST3, ST6 \\
2 July 2009 & 59.0 & 10 & 24.0 & ST1, ST2, ST3, ST4, ST5, ST6 \\
12 July 2009 & 67.9 & 19 & 20.0 & ST1, ST3, ST4, ST5, ST6 \\
15 July 2009 & 41.9 & 10 & 20.0 & ST1, ST3, ST5, ST6 \\
11 August 2009 & 72.9 & 14 & 16.0 & ST1, ST4, ST6 \\
23 May 2010 & 59.8 & 44 & 6.0 & ST2 \\
12 August 2010 & 28.0 & 4 & 16.0 & ST1, ST2, ST3, ST4, ST6 \\
15 August 2010 & 31.0 & 5 & 20.0 & ST1, ST4, ST5, ST6 \\
11 September 2010 & 68.9 & 40 & 21.0 & ST2, ST3, ST4, ST6 \\
\hline
\end{tabular}

\subsection{HSPF Calibration}

HSPF calibration was performed by matching observed stream flow first and then suspended sediment load. The calibration parameters and the description are shown in Table 3. U.S. EPA guides the possible ranges of calibration parameters by land use type related to hydrologic calibration [21] and sediment calibration [22], and HSPF calibration was performed by considering the parameter ranges. Donigian [23] suggested the calibration tolerances for HSPF simulation (Table 4). The performance of calibration for stream flow and suspended sediment loads was evaluated by the criteria.

The determine coefficient $\left(\mathrm{R}^{2}\right)$, the Nash-Sutcliffe (NS) coefficient [24], widely used as an objective function for stream flow calibration, and the relative error (RE) were calculated with Equations (4)-(6), respectively. When the simulated values are exactly matched with the observed values, the determine coefficient, Nash-Sutcliffe coefficient, and relative error are $1.0 \%, 1.0 \%$, and $0.0 \%$, respectively. A positive relative error means simulated values are higher than the observed values. Although simulation results represent observed stream flow or suspended sediment, outliers could negatively affect the results in the statistical analysis. Therefore, one or two outliers were excluded in the statistical analysis in this study.

$$
\mathrm{R}^{2}=\left(\frac{\sum_{\mathrm{i}=1}^{\mathrm{n}}\left(\mathrm{O}_{\mathrm{i}}-\overline{\mathrm{O}}\right)\left(\mathrm{P}_{\mathrm{i}}-\overline{\mathrm{P}}\right)}{\sqrt{\sum_{\mathrm{i}=1}^{\mathrm{n}}\left(\mathrm{O}_{\mathrm{i}}-\overline{\mathrm{O}}\right)^{2}} \sqrt{\sum_{\mathrm{i}=1}^{\mathrm{n}}\left(\mathrm{P}_{\mathrm{i}}-\overline{\mathrm{P}}\right)^{2}}}\right)^{2}
$$




$$
\begin{aligned}
& \mathrm{NS}=1-\left(\frac{\sum_{\mathrm{i}=1}^{\mathrm{n}}\left(\mathrm{O}_{\mathrm{i}}-\mathrm{P}_{\mathrm{i}}\right)^{2}}{\sqrt{\sum_{\mathrm{i}=1}^{\mathrm{n}}\left(\mathrm{O}_{\mathrm{i}}-\overline{\mathrm{O}}\right)^{2}}}\right) \\
& \mathrm{RE}(\%)=\frac{\sum_{\mathrm{i}=1}^{\mathrm{n}}\left(\mathrm{P}_{\mathrm{i}}-\mathrm{O}_{\mathrm{i}}\right)}{\sum_{\mathrm{i}=1}^{\mathrm{n}} \mathrm{O}_{\mathrm{i}}} \times 100
\end{aligned}
$$

where $\mathrm{R}^{2}$ is the coefficient of determination, NS is the Nash-Sutcliffe coefficient, RE is the relative error, $\mathrm{O}_{i}$ is the observed value, $\overline{\mathrm{O}}$ is the average observed value, $\mathrm{P}_{\mathrm{i}}$ is the simulated value, and $\overline{\mathrm{P}}$ is the average simulated value.

\begin{tabular}{|c|c|c|c|c|c|c|}
\hline \multicolumn{2}{|c|}{ Parameter } & \multicolumn{5}{|c|}{ Ranges } \\
\hline & & Upland & Forest & Pasture & Barren & Urban \\
\hline \multirow{9}{*}{ Water budget } & LZSN $(\mathrm{cm})$ & $4.1-20.3$ & $3.8-18.8$ & $4.1-20.3$ & $3.8-18.8$ & \\
\hline & INFILT (cm/h) & $2.0-13.0$ & $1.4-9.2$ & $2.0-13.6$ & $2.5-23.4$ & \\
\hline & UZSN (cm) & $0.2-4.1$ & $0.2-5.1$ & $0.2-4.1$ & $0.1-3.0$ & \\
\hline & NSUR & $0.03-0.3$ & $0.04-0.5$ & $0.03-0.3$ & $0.02-0.3$ & $0.01-0.1$ \\
\hline & AGWRC (/day) & \multicolumn{5}{|c|}{$0.833-0.999$} \\
\hline & $\operatorname{IRC~(/day)~}$ & \multicolumn{5}{|c|}{$0.3-0.85$} \\
\hline & INTFW (/day) & \multicolumn{5}{|c|}{$1.0-10.0$} \\
\hline & DEEPER & \multicolumn{5}{|c|}{$0.0-0.5$} \\
\hline & BASETP & \multicolumn{5}{|c|}{$0.0-0.05$} \\
\hline \multirow{7}{*}{ Sediment } & KRER & \multicolumn{5}{|c|}{$0.05-0.75$} \\
\hline & JRER & \multicolumn{5}{|c|}{$1.0-3.0$} \\
\hline & AFFIX & \multicolumn{5}{|c|}{$0.01-0.50$} \\
\hline & KSER & \multicolumn{5}{|c|}{$0.1-10.0$} \\
\hline & JSER & \multicolumn{5}{|c|}{$1.0-3.0$} \\
\hline & KGER & \multicolumn{5}{|c|}{$0.0-10.0$} \\
\hline & JGER & \multicolumn{5}{|c|}{$1.0-5.0$} \\
\hline
\end{tabular}

Table 3. Description and ranges of Hydrological Simulation Program-FORTRAN (HSPF) parameters.

LZSN: Lower zone nominal soil moisture storage; INFILT: Infiltration capacity of soil; UZSN: Upper zone nominal soil moisture storage; NSUR: Manning's n coefficient; AGWRC: Ground water recession rate; IRC: Interflow recession parameter; INTFW: Interflow inflow parameter; DEEPER: Fraction of groundwater inflow to deep recharge; BASETP: Fraction of evapotranspiration from baseflow; KRER: Detachment coefficient of soil; JRER: Detachment exponent of soil; AFFIX: Daily reduction in detached sediment; KSER: Coefficient for transport of detached sediment; JSER: Exponent for transport of detached sediment; KGER: Coefficient for scour of the matrix soil; JGER: Exponent for scour of the matrix soil.

Table 4. General calibration and validation target or tolerances for HSPF application [23].

\begin{tabular}{cccccc}
\hline \multicolumn{2}{c}{ Calibration Item } & Very Good & Good & Fair & Poor \\
\hline Daily & $\mathrm{R}^{2}$ & $>0.8$ & $0.7-0.8$ & $0.6-0.7$ & $<0.6$ \\
Stream flow & $\mathrm{RE}(\%)$ & $<20$ & $20-30$ & $30-45$ & $>45$ \\
Sediment & $\mathrm{R}(\%)$ \\
\hline
\end{tabular}

\section{Results and Discussion}

\subsection{Calibration Results}

The calibration results of HSPF are shown in Table 5, Figure 4 for hourly stream flow, and Figure 5 for hourly suspended sediment yield. The 1:1 scatter plot and regression analysis between the observed and simulated values are shown in Figures 6 and 7. One or two extra-ordinary data points which contribute to lower NS or relative error were excluded. The coefficients of determination and NS for stream flow ranged from 0.76 to 0.95 and from 0.78 to 0.96 , respectively. The coefficient of determination and relative error for suspended sediment yield calibration ranged from 0.62 to 0.96 , and from $-1 \%$ to $23 \%$, respectively. Although some simulation results underestimated peak points, 
overall, the performance of the HSPF calibration of the stream flow and suspended sediment yield was "good", based on the HSPF calibration tolerance (Table 4). The ranges of calibrated HSPF parameters by six subwatersheds related to water budget and sediment simulation are shown in Table 6 . All of the calibrated parameters for simulating the water budget were within the "possible" range suggested by U.S. EPA.

Monitoring during rainy days is expensive and can sometimes be dangerous, so it is hard to obtain data for calibration and validation processes. Due to these difficulties, it is rare for a case study to calibrate and validate water quality using monitoring data for rainy days. Hsu et al. [25] calibrated and validated stream flow and sediment loads of HSPF simulation using typhoon events. Many case studies in recent (in the last 5 years) research did not perform validation processes for the water quality simulation of HSPF because it is very hard to obtain monitoring data during the rainy season for validation process [26-28]. A validation process was not undertaken in this study. Monitoring data for six events were used for model calibration, which constitutes a limitation of this research.

Table 5. Coefficients of determination of the hourly stream flow calibration.

\begin{tabular}{cccccccc}
\hline Calibration Item & & ST1 & ST2 & ST3 & ST4 & ST5 & ST6 \\
\hline \multirow{2}{*}{ Stream flow } & $\mathrm{R}^{2}$ & 0.80 & 0.76 & 0.95 & 0.86 & 0.89 & 0.93 \\
& $\mathrm{NS}$ & 0.88 & 0.78 & 0.95 & 0.89 & 0.96 & 0.86 \\
\multirow{2}{*}{ Suspended Sediment yields } & $\mathrm{R}^{2}$ & 0.87 & 0.96 & 0.90 & 0.60 & 0.89 & 0.62 \\
& $\mathrm{RE}(\%)$ & 23 & -1 & 22 & -14 & -13 & 16 \\
\hline
\end{tabular}

Table 6. Calibrated HSPF parameters.

\begin{tabular}{|c|c|c|c|c|c|c|}
\hline \multirow{2}{*}{\multicolumn{2}{|c|}{ Parameter }} & \multicolumn{5}{|c|}{ Ranges } \\
\hline & & Upland & Forest & Pasture & Barren & Urban \\
\hline \multirow{9}{*}{ Water budget } & LZSN (cm) & $7.7-16.1$ & $7.58-8.96$ & $5.08-13.83$ & 7.19-18.75 & \multirow{9}{*}{0.05} \\
\hline & INFILT (cm/h) & $0.18-0.20$ & 0.13 & $0.04-0.54$ & $0.22-0.46$ & \\
\hline & $\operatorname{UZSN}(\mathrm{cm})$ & $0.19-0.23$ & $0.25-0.26$ & $0.17-0.26$ & $0.13-0.26$ & \\
\hline & NSUR & $0.21-0.34$ & 0.37 & $0.11-0.25$ & $0.05-0.27$ & \\
\hline & AGWRC (/day) & & & $0.88-0.91$ & & \\
\hline & $\operatorname{IRC~(/day)~}$ & & & 0.40 & & \\
\hline & INTFW & & & $1.97-2.01$ & & \\
\hline & DEEPER & & & 0.45 & & \\
\hline & BASETP & & & 0.02 & & \\
\hline \multirow{6}{*}{ Sediment } & KRER & & & $0.05-0.40$ & & \\
\hline & JRER & & & $1.00-2.57$ & & \\
\hline & KSER & & & $0.10-2.00$ & & \\
\hline & JSER & & & $2.00-3.00$ & & \\
\hline & KGER & & & $0.0001-1.70$ & & \\
\hline & JGER & & & $2.50-5.00$ & & \\
\hline
\end{tabular}

LZSN: Lower zone nominal soil moisture storage; INFILT: Infiltration capacity of soil; UZSN: Upper zone nominal soil moisture storage; NSUR: Manning's n coefficient; AGWRC: Ground water recession rate; IRC: Interflow recession parameter; INTFW: Interflow inflow parameter; DEEPER: Fraction of groundwater inflow to deep recharge; BASETP: Fraction of evapotranspiration from baseflow; KRER: Detachment coefficient of soil; JRER: Detachment exponent of soil; AFFIX: Daily reduction in detached sediment; KSER: Coefficient for transport of detached sediment; JSER: Exponent for transport of detached sediment; KGER: Coefficient for scour of the matrix soil; JGER: Exponent for scour of the matrix soil. 

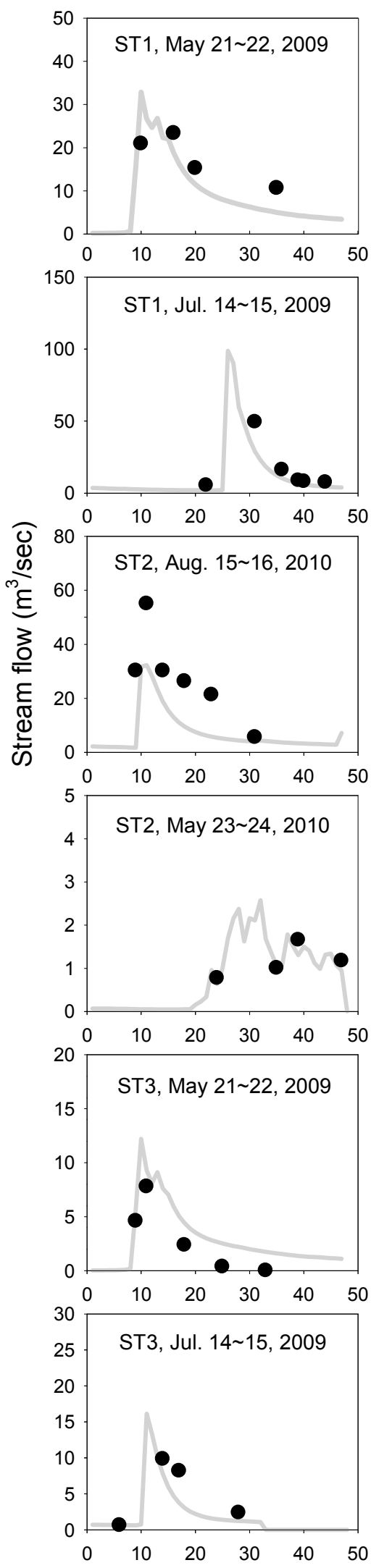
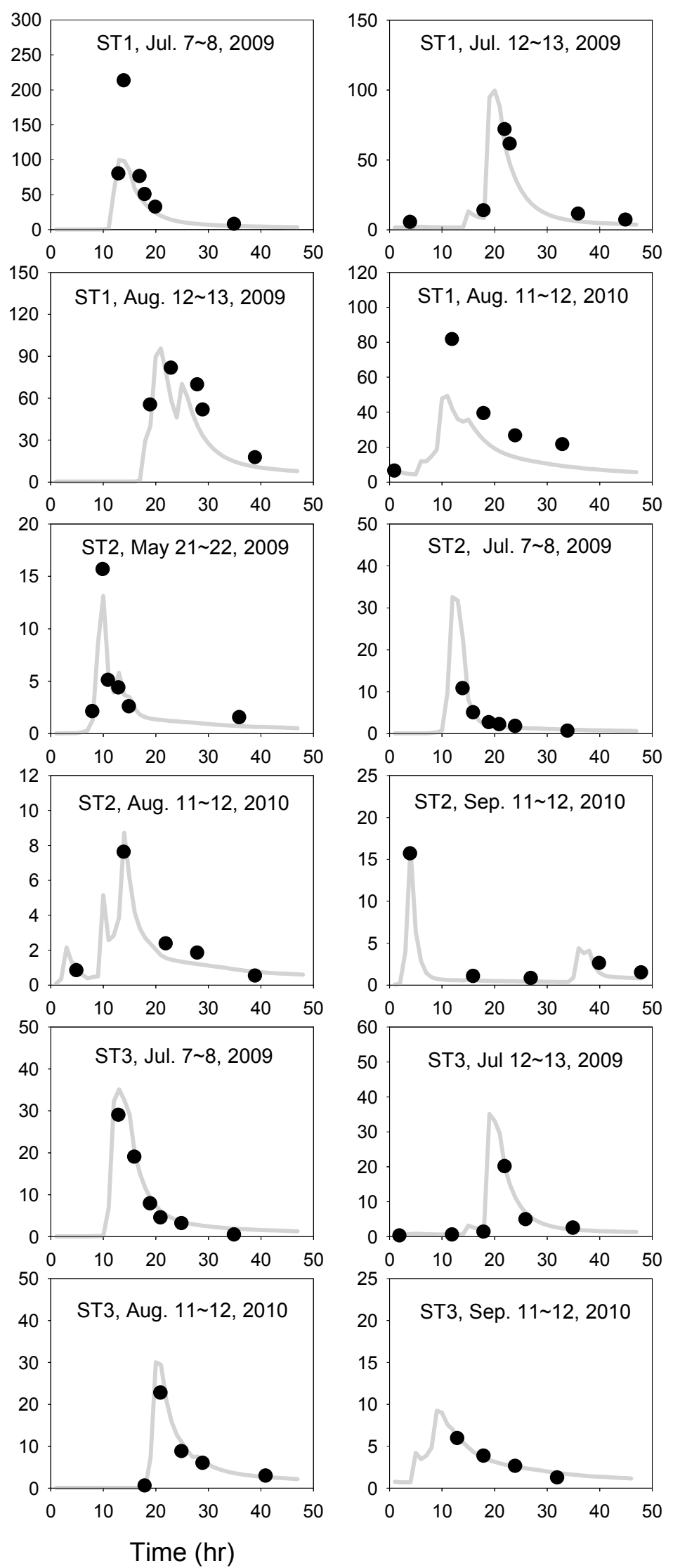

Figure 4. Cont. 


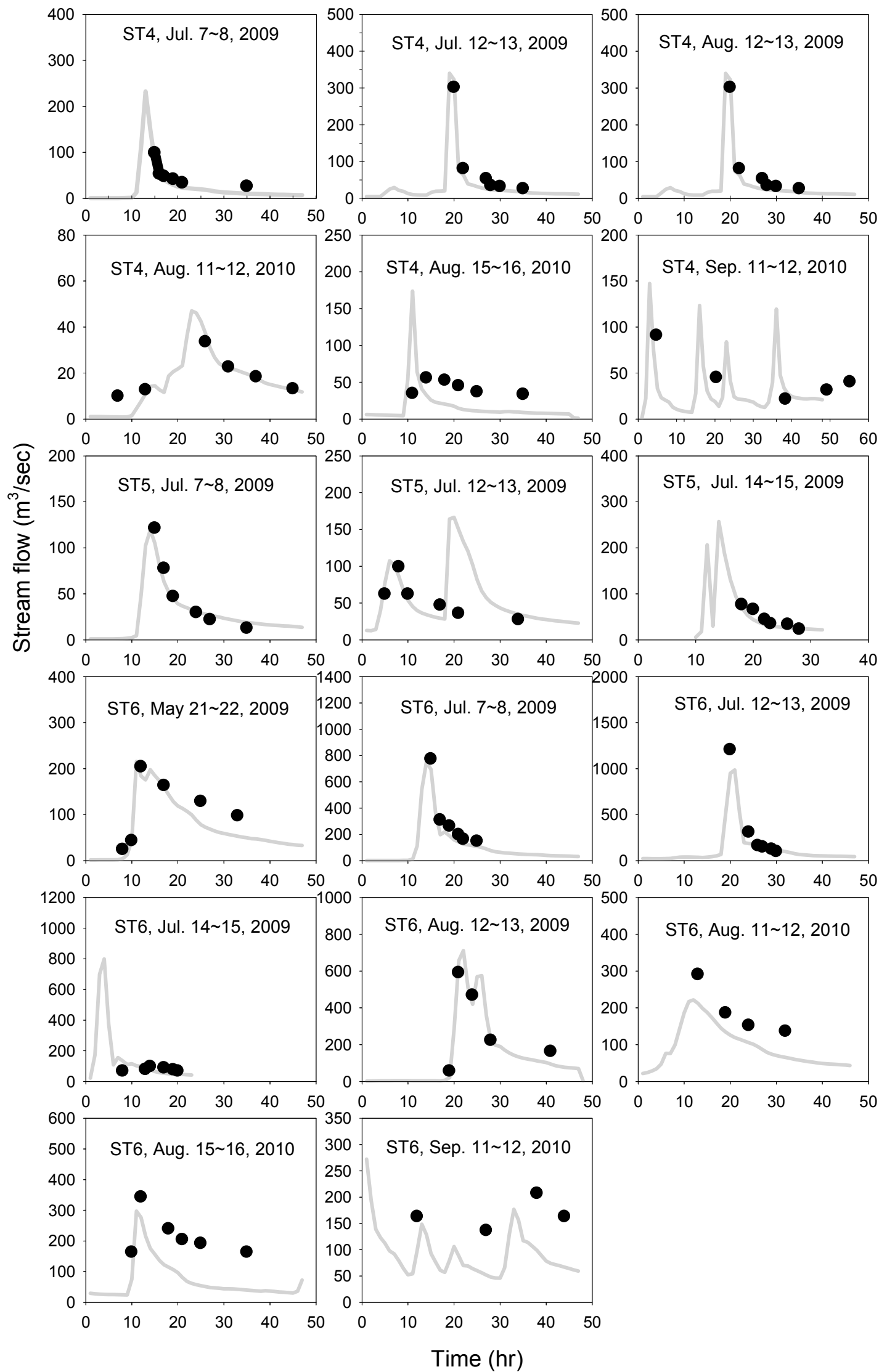

Figure 4. Stream flow calibration. The black point and gray line are observed and simulated data, respectively. 


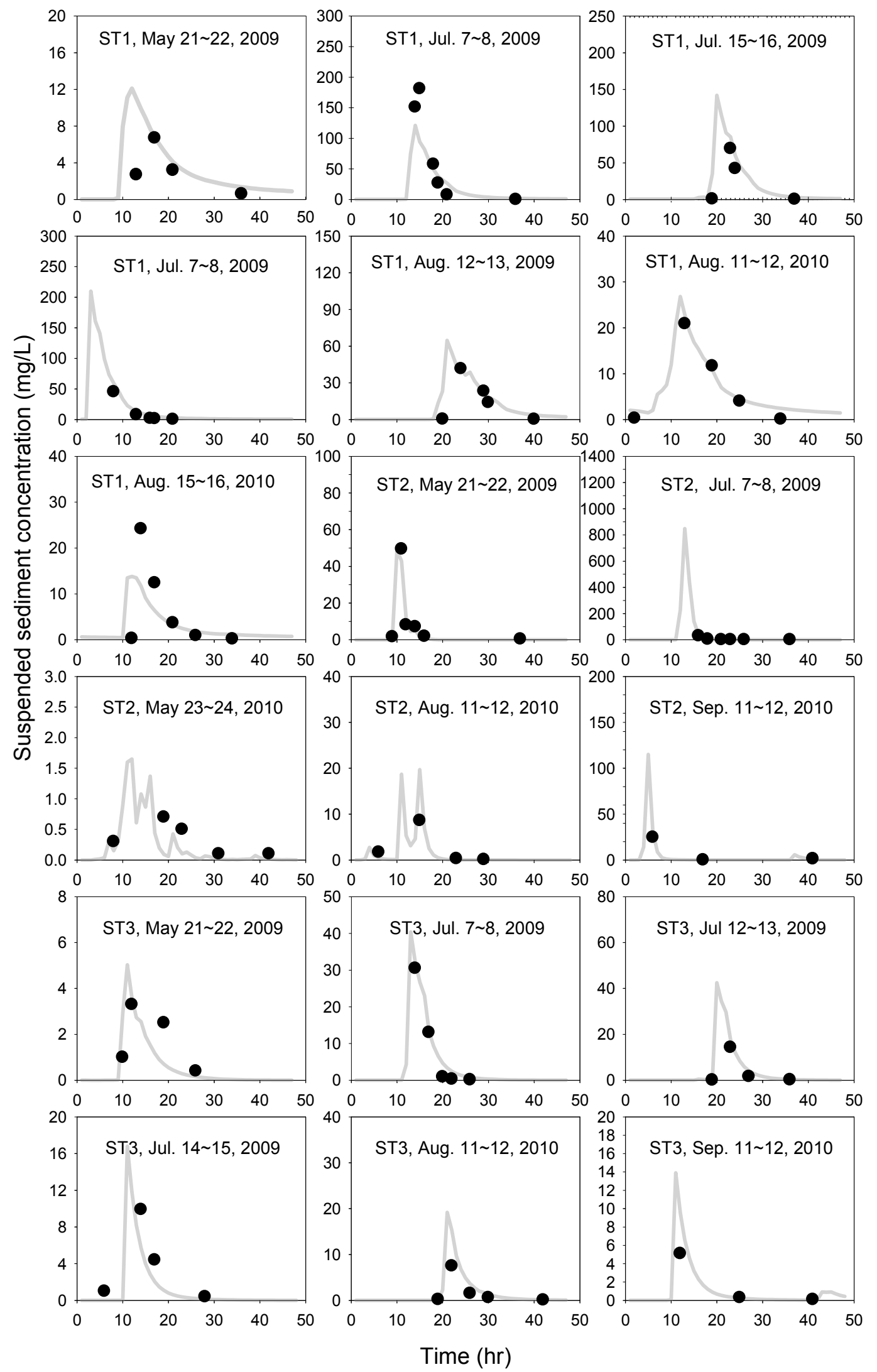

Figure 5. Cont. 

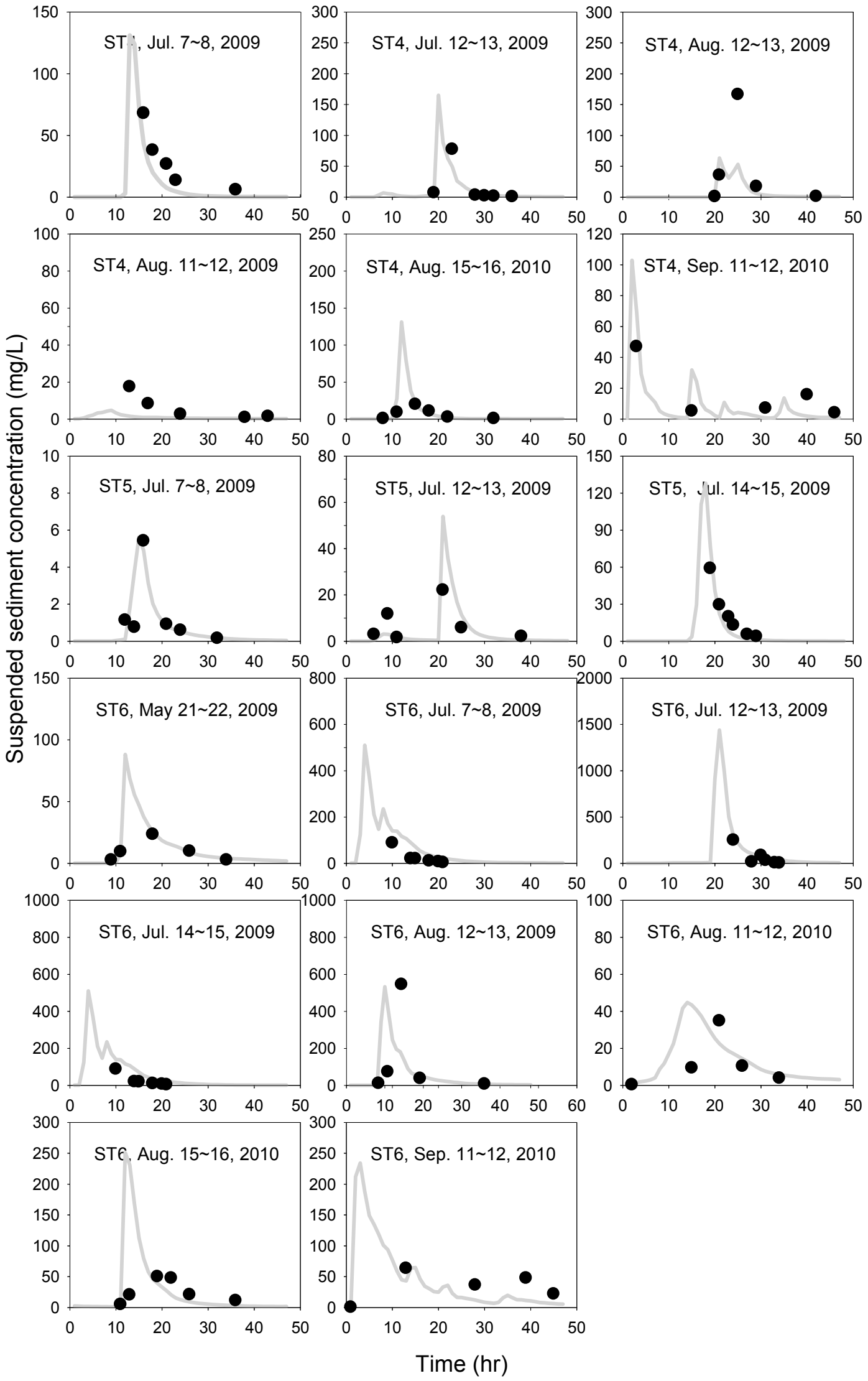

Figure 5. Suspended sediment calibration. The black point and gray line are observed and simulated data, respectively. 

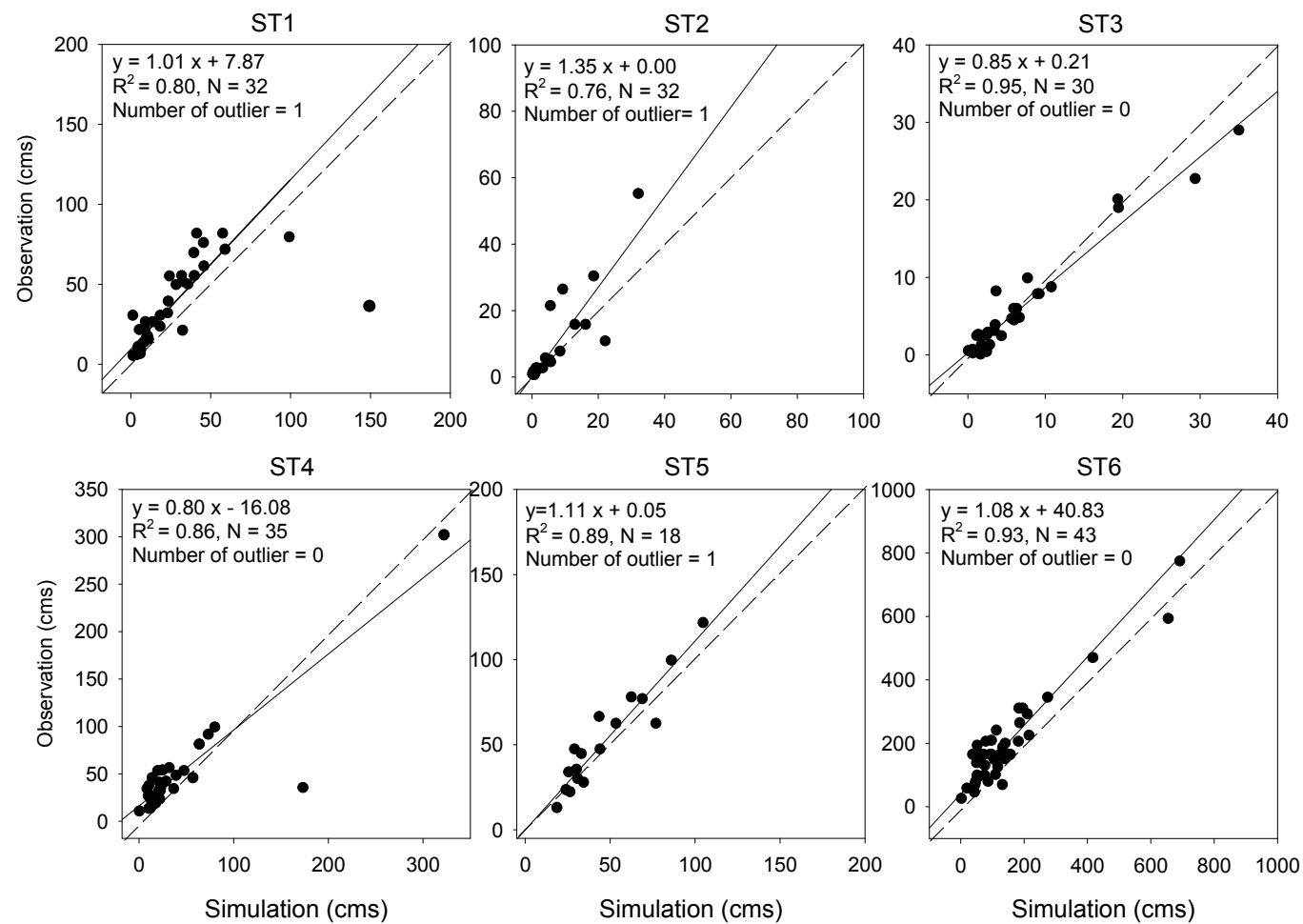

Figure 6. Scatter plot between observed and simulated hourly stream flow.
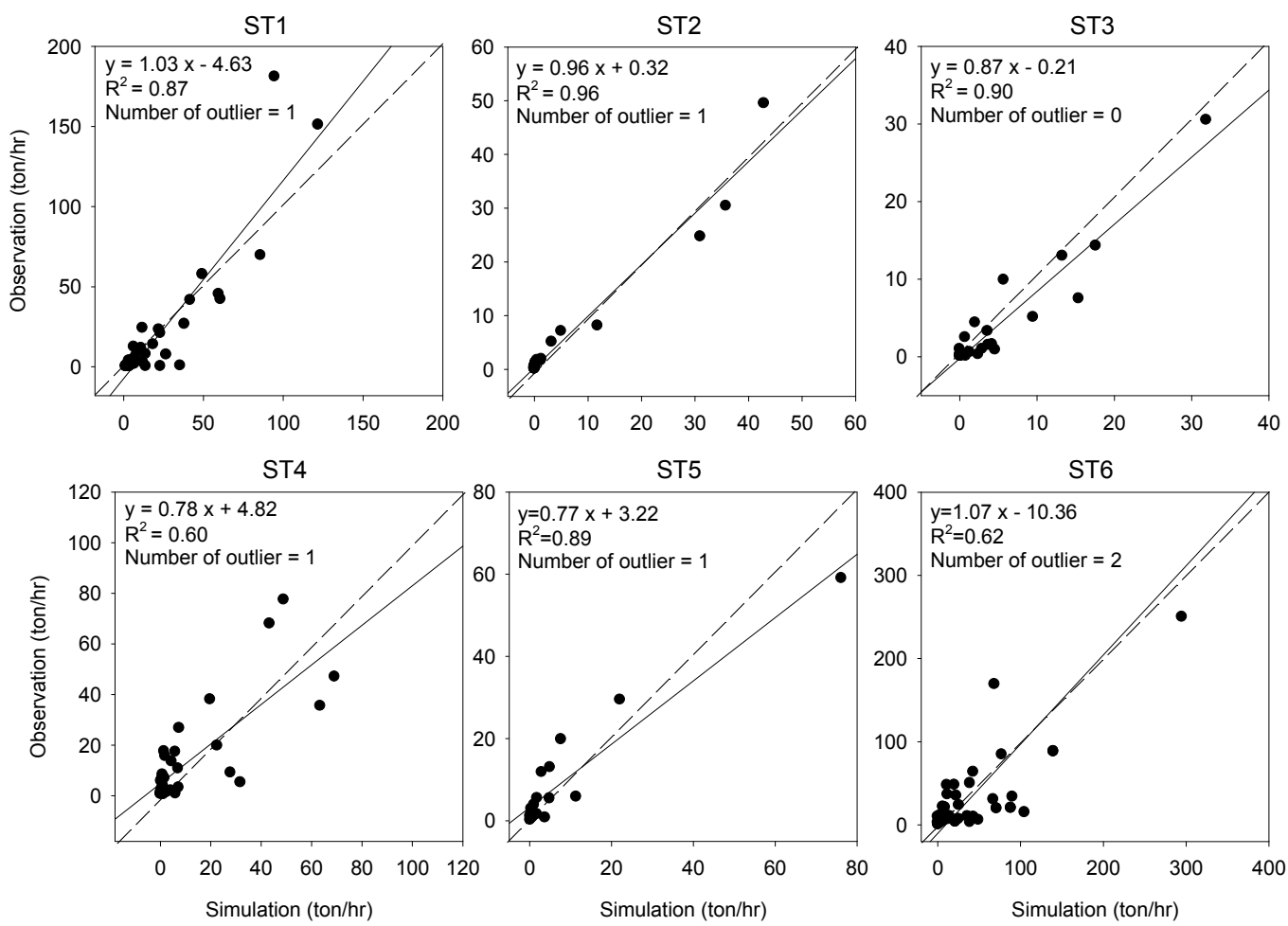

Figure 7. 1:1 scatter plots between observed and simulated suspended sediment loads.

\subsection{Characteristics of Suspended Sediment Loadings under the East Asian Monsoon Climate}

One of the characteristics of the East Asian monsoon climate is extreme precipitation or annual variabilities [29]. Annual variability of precipitation could influence the annual suspended sediment 
loads because suspended sediment load is highly dependent on rainfall intensity. There was significant variance in the yearly suspended sediment loads in ST5 and ST6 as shown in Figure 8 and Table 7. Yearly suspended sediment loads ranged from 6873 to 73,955 ton/year from ST5 and from 6454 to 60,787 ton/year from ST6, and the standard deviation of yearly sediment loads was 19,869 ton/year for ST5 and 15,527 ton/year for ST6 (Table 7). The maximum yearly suspended sediment loads were around 10 times higher than the minimum value during 2001-2010 in ST5 and ST6 (Table 7).

Table 7. Statistical analysis for yearly suspended sediment loads during 2001-2010 at ST5 and 6 (ton/year).

\begin{tabular}{cccccc}
\hline Station ID & Average & Maximium & Minimum & Max/Min * & STD $^{* *}$ \\
\hline ST5 & 29,187 & 73,955 & 6873 & 11 & 19,869 \\
ST6 & 22,646 & 60,787 & 6454 & 9 & 15,527 \\
\hline \multicolumn{7}{c}{}
\end{tabular}

* Maximum/Minimum; ** Standard deviation.

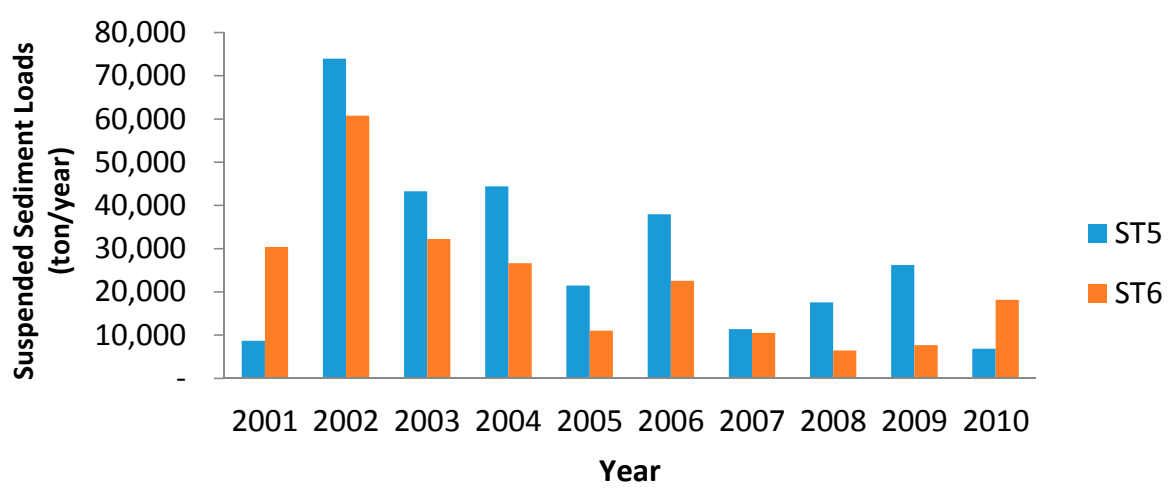

Figure 8. Suspended sediment loads from ST5 and ST6 during 2001 to 2010.

Another characteristic of sediment loads under the East Asian monsoon climate is that a significant amount of sediment was loaded during one event (Table 8). Heo et al. [30] reported that $22 \%-33 \%$ of total suspended sediments are loaded by typhoon under an Asian summer monsoon climate. Based on the average value during 2001-2010, over half of the yearly suspended sediment was loaded during one event ranging from $26 \%$ to $94 \%$ for ST5 and from $29 \%$ to $90 \%$ for ST6. More than $90 \%$ of yearly suspended sediment was loaded by one event at ST5 in 2008 and at ST6 for 2006.

Table 8. Comparison of yearly suspended sediment loads and load during one event.

\begin{tabular}{|c|c|c|c|c|c|c|}
\hline \multirow{2}{*}{ Year } & \multicolumn{3}{|c|}{ ST5 } & \multicolumn{3}{|c|}{ ST6 } \\
\hline & Yearly * & Event ** & Ratio *** & Yearly & Event & Ratio \\
\hline 2001 & 8711 & 4090 & 0.47 & 30,398 & 20,205 & 0.66 \\
\hline 2002 & 73,955 & 37,283 & 0.50 & 60,787 & 25,202 & 0.41 \\
\hline 2003 & 43,284 & 11,085 & 0.26 & 32,210 & 10,233 & 0.32 \\
\hline 2004 & 44,412 & 16,575 & 0.37 & 26,666 & 9714 & 0.36 \\
\hline 2005 & 21,473 & 17,076 & 0.80 & 11,038 & 5420 & 0.49 \\
\hline 2006 & 37,953 & 29,353 & 0.77 & 22,554 & 20,260 & 0.90 \\
\hline 2007 & 11,409 & 5339 & 0.47 & 10,537 & 3019 & 0.29 \\
\hline 2008 & 17,579 & 16,465 & 0.94 & 6454 & 3676 & 0.57 \\
\hline 2009 & 26,222 & 18,213 & 0.69 & 7661 & 4447 & 0.58 \\
\hline 2010 & 6873 & 2922 & 0.43 & 18,149 & 12,504 & 0.69 \\
\hline Average & 29,187 & 15,840 & 0.54 & 22,646 & 11,468 & 0.51 \\
\hline
\end{tabular}

* Yearly suspended sediment loads; ** Suspended sediment loads by one event; *** Ratio of load by one event to yearly load. 
Suspended sediment is a major nonpoint source of pollution in the world. Many countries have tried to reduce suspended sediment load from the watershed by developing best management practices (BMPs). The size or volume of structural BMPs is influenced by the volume of storm water, so when establishing structural BMPs, the particular characteristics of the suspended sediment load under the East Asian monsoon climate must be considered.

Monitoring under all weather conditions is practically impossible. In this study, sediment loading for calibration periods is smaller than that for simulation periods as shown in Figure 8 and Table 8, so it may be possible that there is systematic error in the estimates of sediment loadings during very rainy years.

\section{Conclusions}

HSPF was calibrated during 2009-2010 to simulate the suspended sediment loads at six monitoring stations within the Imha Lake watershed, Korea. The stream flow and suspended sediment load were monitored at every $4-15 \mathrm{~h}$ during high water flow. The calibration results showed that HSPF could effectively simulate the patterns of hourly change of suspended sediment loads and stream flow, showing $0.59-0.96$ for the Nash-Sutcliffe coefficients for stream flow, and $-29 \%-17 \%$ of relative errors for the suspended sediment loads. The extreme variance of amount of yearly and rainfall intensity by typhoon under the East Asian monsoon climate could greatly influence the suspended sediment load from the watershed. During 2001-2010, the maximum yearly suspended sediment load was around 10 times higher than the minimum yearly value at the same monitoring site. Overall, suspended sediment load by a single rainfall event was up to half of the yearly suspended sediment load and 90\% in certain years under the East Asian monsoon climate. When developing BMPs for controlling suspended sediment, the characteristics of the suspended sediment load under the East Asia monsoon climate must be considered in their design.

Acknowledgments: This work was supported by a grant from 2015 Research Funds of Andong National University.

Author Contributions: Ji-Hong Jeon wrote the paper and applied HSPF. Donghyuk Choi monitored analyzed water and suspended sediment load. Chan-Gi Park reviewed the modeling approaches and Taedong Kim directed this research and writing the paper.

Conflicts of Interest: The authors declare no conflict of interest.

\section{References}

1. Park, S.; Oh, C.; Jeon, S.; Jung, H.; Choi, C. Soil erosion risk in Korea watersheds, assessed using the revised universal soil loss equation. J. Hydrol. 2011, 399, 263-273. [CrossRef]

2. U.S. Environmental Protection Agency (EPA). EPA 841-B-99-004 Protocol for Developing Sediment TMDLs, 1st ed.; U.S. EPA: Washington, DC, USA, 1999.

3. Crabill, C.; Donald, R.; Snelling, J.; Foust, R.; Southam, G. The impact of sediment fecal coliform reservoirs on seasonal water quality in Oak Creek, Arizona. Water Res. 1999, 33, 2163-2171. [CrossRef]

4. Somura, H.; Takeda, I.; Arnold, J.G.; Mori, Y.; Jeong, J.; Kannan, N.; Hoffman, D. Impact of suspended sediment and nutrient loading from land uses against water quality in the Hii River basin, Japan. J. Hydrol. 2012, 450-451, 25-35. [CrossRef]

5. Renard, K.G.; Foster, G.R.; Weesies, G.A.; Porter, J.P. RUSLE: Revised universal soil loss equation. J. Soil Water Conserv. 1991, 46, 30-33.

6. Meng, L.; Feng, Q.; Wu, K.; Meng, Q. Quantitave evalustion of soil erosion of land subsided by coal mining using RUSLE. Int. J. Min. Sci. Technol. 2012, 22, 7-11. [CrossRef]

7. Nyakatawa, E.Z.; Jakkula, V.; Reddy, K.C.; Lemunyon, J.L.; Norris, B.E. Soil erosion estimation in conservation tillage systems with poultry litter application using RUSLE 2.0 model. Soil Tillage Res. 2007, 94, 410-419. [CrossRef]

8. Fu, G.; Chen, S.; McCool, D.K. Modeling the impacts of no-till practice on soil erosion and sediment yield with RUSLE, SEDD, and ArcView GIS. Soil Tillage Res. 2006, 85, 38-49. [CrossRef] 
9. Neitsch, S.L.; Arnold, J.G.; Kiniry, J.R.; Williams, J.R. TR-406 Soil and Water Assessment Tool Theoretical Documentation Version 2009; Texas Water Resources Institute: College Station, TX, USA, 2011.

10. Qiu, L.J.; Zheng, F.L.; Yin, R.S. SWAT-based runoff and sediment simulation in a small watershed, the loessial hilly-gullied region of China: Capabilities and challenges. Int. J. Sediment Res. 2012, 27, 226-234. [CrossRef]

11. Oeurng, C.; Sauvage, S.; Sánchez-Pérez, J.M. Assessment of hydrology, sediment and particulate organic carbon yield in a large agricultural catchment using the SWAT model. J. Hydrol. 2011, 401, 145-153. [CrossRef]

12. Sommerlot, A.R.; Nejadhashemi, A.P.; Woznicki, S.A.; Giri, S. Evaluating the capabilities of watershed-scale models in estimating sediment yield at field-scale. J. Environ. Manag. 2013, 127, 228-236. [CrossRef] [PubMed]

13. U.S. Environmental Protection Agency (EPA). EAP841-B-97-006 Compendium of Tool for Watershed Assessment and TMDL Development; U.S. EPA: Washington, DC, USA, 1997.

14. Ouyang, Y.; Leininger, T.D.; Moran, M. Impact of reforestation upon sediment load and water outflow in the Lower Yazoo River Watershed, Mississippi. Ecol. Eng. 2013, 61, 394-406. [CrossRef]

15. Hunter, H.M.; Walton, R.S. Land-use effects on fluxes of suspended sediment, nitrogen and phosphorus from a river catchment of the Great Barrier Reef, Australia. J. Hydrol. 2008, 356, 131-146. [CrossRef]

16. Benaman, J.; Shoemaker, C.A. An analysis of high-flow sediment event data for evaluating model performance. Hydrol. Process 2005, 19, 605-620. [CrossRef]

17. Thompson, J.; Cassidy, R.; Doody, D.G.; Flynn, R. Assessing suspended sediment dynamics in relation to ecological thresholds and sampling strategies in two Irish headwater catchments. Sci. Total Environ. 2013, 468-469, 345-357. [CrossRef] [PubMed]

18. Bicknell, B.R.; Imhoff, J.C.; Kittle, J.L.; Jobes, T.H.; Donigian, A.S. HSPF Version 12 User's Manual; AQUA TERRA Consultants: Mountain View, CA, USA, 2004.

19. Shin, M.J.; Eun, J.J.; Seo, E.W. Changes of gill structure and identification of genes by muddy water exposure in Cyprinus Carpio. Korean J. Limnol. 2011, 44, 95-101.

20. Kim, S.H. Influence of Muddy Water in Imha Reservoir on the Community Fluctuation of Benthic Macroinvertebrates and Food Selection of Fishes. Master's Thesis, Andong National University, Andong, Korea, 2009.

21. U.S. Environmental Protection Agency (EPA). Basins Technical Note 6: Estimating Hydrology and Hydraulic Parameters for HSPF; U.S. EPA: Washington, DC, USA, 2000.

22. U.S. Environmental Protection Agency (EPA). Basins Technical Note 8: Sediment Parameter and Calibration Guidance for HSPF; U.S. EPA: Washington, DC, USA, 2006.

23. Donigian, A.S. Watershed Model Calibration and Validation: The HSPF Experience. In Proceedings of the National TMDL Science and Policy Specialty Conference 2002, Phoenix, AR, USA, 13-16 November 2002.

24. Nash, J.E.; Sutcliffe, J.V. Reiver flow forecasting through conceptual model. Part 1. A discussion of principles. J. Hydrol. 1970, 10, 282-290. [CrossRef]

25. Hsu, S.M.; Wen, H.Y.; Chen, N.C.; Hsu, S.Y.; Chi, S.Y. Using an integrated method to estimate watershed sediment yield during heavy rain period: A case study in Hualien County, Taiwan. Nat. Hazards Earth Syst. Sci. 2012, 12, 1949-1960. [CrossRef]

26. Betrie, G.D.; Mohamed, Y.A.; van Griensven, A.; Srinivasan, R. Sediment management modeling in the Blue Nile Basin using SWAT model. Hydrol. Earth Syst. Sci. 2011, 15, 807-818. [CrossRef]

27. Lenzi, M.A.; Marchi, L. Suspended sediment load during floods in a small stream of the Dolomites (northeastern Italy). CATENA 2000, 39, 267-282. [CrossRef]

28. Saleh, A.; Du, B. Evaluation of SWAT and HSPF within BASINS program for the Upper North Bosque River Watershed in Central Texas. Trans. ASAE 2004, 47, 1039-1049.

29. Lau, K.-M.; Yang, G.J.; Shen, S.H. Seasonal and intraseasonal climatology of summer monsoon rainfall over East Asia. Mon. Weather Rev. 1987, 116, 18-37. [CrossRef]

30. Heo, S.G.; Kim, K.S.; Sagong, M.; Ahn, J.H.; Lim, K.J. Evaluation of SWAT applicability to simulate soil erosion at highland agricultural lands. J. Korean Soc. Rural Plan. 2005, 11, 67-74.

(C) 2016 by the authors; licensee MDPI, Basel, Switzerland. This article is an open access article distributed under the terms and conditions of the Creative Commons Attribution (CC-BY) license (http:/ / creativecommons.org/licenses/by/4.0/). 